\title{
Testes de vigor utilizados na avaliação da qualidade fisiológica de lotes de sementes de milho-doce (sh2)
}

\author{
Vigor tests for selection of sweet corn (sh2) seeds lot
}

\author{
Rogério de Andrade Coimbra ${ }^{I}$ Cibele Chalita Martins ${ }^{I I}$ Camila de Aquino Tomaz ${ }^{I I}$ \\ João NakagawaII
}

\section{RESUMO}

Dentro de um programa de controle de qualidade, a avaliação do vigor de sementes é fundamental e necessária para o sucesso da produção. Com o objetivo de avaliar a eficiência de diferentes testes de vigor na avaliação da qualidade fisiológica de sementes de milho-doce na tentativa de diferenciação de lotes quanto ao nível de vigor e previsão de emergência de plântulas em campo e ao potencial de armazenamento, 10 lotes do híbrido DO-04 shrunken-2 (sh-2) foram submetidos a teste de germinação, primeira contagem, precocidade de emissão de raiz primária (32, 48, 56 e 72h), teste de frio, condutividade elétrica (50 sementes $75 \mathrm{~mL}^{-1}$ de água; $25^{\circ} \mathrm{C} / 4,6,8$ e $\left.24 \mathrm{~h}\right)$, envelhecimento acelerado $\left(42^{\circ} \mathrm{C}\right)$ em água destilada (100\%UR), solução saturada de cloreto de potássio (87\%UR) e solução saturada de cloreto de sódio (76\% UR), avaliando-se quatro períodos de exposição (24, 48, 72 e 96h), teor de água, emergência de plântulas em campo e germinação após armazenamento das sementes $\left(10^{\circ} \mathrm{C}\right.$ e 40\%UR), avaliada quadrimestralmente por 16 meses. A condutividade elétrica (por 6, 8 e 24h) foi o único teste eficiente na diferenciação do vigor de lotes de sementes de milho-doce (sh2); no entanto, não apresentou correlação com a emergência de plântulas em campo ou armazenamento.

Palavras-chave: armazenamento, emergência de plântulas, condutividade elétrica, teste de frio, envelhecimento acelerado.

\section{ABSTRACT}

In a program of seed quality assurance, the evaluation of seed vigor is fundamental and necessary to the global production process outcome. The objective of this experiment was to verify the efficiency of different vigor tests for evaluation of sweet corn seeds quality towards lots differentiation and prevision of seedling emergence and storage capacity of those. Ten lots of DO-04 shrunken-2 (sh2) hybrid sweet corn seeds were submitted to the following evaluations: germination, first counting of germination test, earliness of primary root emission (32, 48, 56 and 72 hours), cold test, electrical conductivity test (50 seeds into $75 \mathrm{ml}$ of water, at $25^{\circ} \mathrm{C}$ for 4,6 , 8 and 24 hours), accelerated aging test $\left(42^{\circ} \mathrm{C}\right)$ in distilled water $(100 \% R H)$, potassium chloride saturated solution ( $87 \%$ $\mathrm{RH}$ ) and sodium chloride saturated solution (76\% RH). Four exposition periods (24, 48, 72 and 96 hours) were evaluated and also seed water content, field seedlings emergence and germination after seeds storage $\left(10^{\circ} \mathrm{C}\right.$ and $\left.40 \% \mathrm{RH}\right)$ during sixteen months. The electrical conductivity test (for 6, 8 and 24 hours) was the unique test efficient to distinguish vigor of sweet corn (sh2) seeds lots, but it did not present correlation with field seedlings emergence or storage capacity.

Key words: storage, seedling emergence, electrical conductivity, cold test, accelerated aging.

\section{INTRODUÇÃO}

A qualidade fisiológica das sementes tem recebido a atenção de muitos pesquisadores, de forma que vários trabalhos de pesquisa na área de sementes têm se concentrado em estudar os testes de vigor, na tentativa de identificar aqueles com maior sensibilidade e eficiência para diferenciar os lotes quanto ao nível de vigor (VIEIRA \& CARVALHO, 1994). Outra linha importante de pesquisa é o estudo do potencial de armazenamento das sementes, o qual tem relação com o vigor das mesmas (DELOUCHE \& BASKIN, 1973; MARCOS FILHO, 1999). Portanto, sementes mais vigorosas são mais resistentes ao armazenamento sob

'Universidade Federal de Mato Grosso (UFMT). Av. Alexandre Ferronato, 1200, 78550-000, Sinop, MT, Brasil. E-mail: rcoimbra@ufmt.br. Autor para correspondência.

"Faculdade de Ciências Agrárias, Universidade Estadual Paulista "Júlio de Mesquita Filho" (UNESP), Botucatu, SP, Brasil. 
condições desfavoráveis de temperatura e umidade do que aquelas sementes com baixo nível de vigor. $\mathrm{Na}$ avaliação do desempenho das sementes em condições de campo, também tem sido relevante tal consideração, pois os resultados obtidos nos testes de germinação superestimam o potencial físiológico das sementes (WATERS \& BLANCHETTE, 1983). No campo, as sementes estão sujeitas a condições adversas, podendo sofrer influência do meio ambiente. Logo, é importante estudar os fatores de campo, pois, se estes não forem ideais, a emergência das plântulas será afetada, prejudicando posteriormente a produção da cultura.

As sementes de milho-doce apresentam a espessura reduzida do pericarpo e maior quantidade de açúcares no endosperma, o que as torna mais suscetíveis aos danos mecânicos, à entrada e proliferação de patógenos e à deterioração, quando comparadas às de milho comum (WATERS \& BLANCHETTE, 1983).

Para assegurar a boa qualidade dos lotes de sementes de milho-doce, as empresas produtoras realizam, normalmente, a colheita no período do outono e inverno, para evitar altas precipitações e temperaturas. Porém, a semeadura e a demanda por sementes são distribuídas ao longo do ano, visando a atender a indústria de milho verde processado, o que torna necessário o armazenamento e a classificação adequada dos lotes, quanto ao vigor.

Os testes de vigor e de germinação auxiliam nas decisões internas das empresas produtoras de sementes quanto ao destino dos lotes, bem como quanto às prioridades de comercialização, de regiões de distribuição e de armazenamento (VIEIRA \& CARVALHO, 1994).

Alguns testes de vigor podem ser realizados conjuntamente com o teste de germinação. A primeira contagem de germinação, realizada para facilitar a condução do teste de germinação, pode ser considerada como um teste de vigor, pois a velocidade da germinação é uma das primeiras características a serem afetadas no processo de deterioração das sementes (VIEIRA \& CARVALHO, 1994). Utilizando o mesmo princípio, pode-se avaliar o vigor de um lote pela precocidade da emissão da raiz primária, com grande eficiência, como foi observado para sementes de milho comum (TOLEDO et al., 1999).

Outro teste rápido de vigor, o da condutividade elétrica, avalia indiretamente a qualidade das sementes e baseia-se na concentração de eletrólitos lixiviados pelas sementes durante a embebição, fornecendo resultados no prazo máximo de 24 horas
(VIEIRA \& CARVALHO, 1994). Pesquisas realizadas com sementes de olerícolas e de grandes culturas têm demonstrado que o decréscimo na germinação e no vigor é diretamente proporcional ao aumento da concentração de eletrólitos liberados pelas sementes durante a embebição.

Um teste amplamente utilizado em programas de controle de qualidade de instituições e empresas para a avaliação das sementes de milho é o de frio, que foi desenvolvido na área denominada de cinturão do milho, localizada nos Estados Unidos da América, e sua metodologia busca simular as condições desfavoráveis que ocorrem com freqüência nesta região durante a época de semeadura, como o excesso de água no solo e as temperaturas baixas. Este teste seleciona como mais vigorosos os lotes com maior germinação nessas condições e, por isso, é classificado como um teste de estresse (VIEIRA \& CARVALHO, 1994).

Outro teste de vigor baseado no estresse e sugerido para a avaliação de sementes de milho pela International Seed Testing Association (ISTA) é o envelhecimento acelerado (MARCOS FILHO, 1999). Esse teste fundamenta-se no aumento da deterioração das sementes por meio da exposição às condições de temperatura e umidade relativa consideradas altas (40 a $45^{\circ} \mathrm{C}$ e $100 \% \mathrm{UR}$ ), que são os fatores ambientais mais relacionados à deterioração das sementes (DELOUCHE \& BASKIN, 1973).

Alguns métodos alternativos para o teste de envelhecimento acelerado têm sido estudados para espécies cujas sementes embebem e deterioram-se rapidamente, de modo similar às sementes de milhodoce. Assim, JIANHUA \& McDONALD (1996) propuseram a substituição da água destilada por soluções saturadas de sais no interior das caixas plásticas utilizadas no teste por promoverem a redução da umidade relativa ( $\mathrm{KCl}-87 \%$ de UR, $\mathrm{NaCl}-76 \%$ de UR, $\mathrm{NaBr}-55 \%$ de UR). Essa alteração de metodologia proporciona menor velocidade de hidratação das sementes, menor teor de água ao final do teste, minimiza as variações de hidratação das sementes e dos resultados, de forma a proporcionar maior eficiência na avaliação do vigor (PANOBIANCO \& MARCOS FILHO, 2001).

Assim, o presente trabalho foi conduzido com o objetivo de verificar a eficiência de diferentes testes de vigor na avaliação da qualidade fisiológica de sementes de milho-doce para a diferenciação de lotes e previsão de emergência de plântulas em campo e armazenamento. 


\section{MATERIAL E MÉTODOS}

No trabalho, foram utilizados 10 lotes de sementes de milho-doce superdoce híbrido DO-04 shrunken-2 (sh2), produzidos sob irrigação e colhidos em agosto de 2003, na região de Guaira, SP, sendo essas sementes classificadas para a uniformização do tamanho em peneiras de crivos redondos, com diâmetro entre 7,14 e 6,35mm (18/64" e 16/64"). As amostras médias de $5 \mathrm{~kg}$ de sementes por lote foram enviadas ao Laboratório de Análise de Sementes do Departamento de Produção Vegetal da FCA/UNESP, em Botucatu, SP, para as seguintes avaliações:

Teste de germinação - conduzido na temperatura de $30^{\circ} \mathrm{C}$, com oito subamostras de 50 sementes por lote, em rolo de papel toalha, determinando-se a porcentagem de plântulas normais, avaliadas no quarto e no sétimo dia após a instalação do teste (BRASIL, 1992).

Precocidade de emissão da raiz primária realizada conjuntamente com o teste de germinação, contabilizando-se a porcentagem de sementes que emitiram a raiz primária após $32,48,56$ e 72 horas da instalação do teste (TOLEDO et al., 1999).

Primeira contagem de germinação - realizada conjuntamente com o teste de germinação, registrandose a porcentagem de plântulas normais presentes no quarto dia após a semeadura (BRASIL, 1992).

Teste de frio - conduzido com quatro subamostras de 50 sementes para cada lote, em rolos de papel toalha umedecidos com água destilada na quantidade de 2,5 vezes a massa do substrato e mantidos à temperatura de $10^{\circ} \mathrm{C}$ durante sete dias e a $30^{\circ} \mathrm{C}$ por quatro dias, avaliando-se a porcentagem de plântulas normais ao final do período (VIEIRA \& CARVALHO, 1994).

Condutividade elétrica - foram utilizadas quatro subamostras de 50 sementes por lote, pesadas em balança com precisão de $0,01 \mathrm{~g}$, colocadas em copos plásticos com $75 \mathrm{~mL}$ de água destilada, em câmaras de germinação a $25^{\circ} \mathrm{C}$ por $4,6,8$ e 24 horas. Decorridos esses períodos, a condutividade elétrica da solução foi determinada em condutivímetro, e os valores médios foram calculados e expressos em $\mu \mathrm{S} \mathrm{cm}-1 \mathrm{~g}-1 \mathrm{de}$ semente (VIEIRA\& CARVALHO, 1994).

Envelhecimento acelerado (100\%UR) conduzido com uma camada única de sementes sobre tela de arame em caixa plástica transparente $(11,0 \times 11,0$ $\mathrm{x} 3,5 \mathrm{~cm})$ contendo $40 \mathrm{~mL}$ de água destilada ( $100 \% \mathrm{UR})$, mantida a $42^{\circ} \mathrm{C}$ por $24,48,72 \mathrm{e} 96$ horas (HAMPTON \& TEKRONY, 1995), seguido do mesmo procedimento do teste de germinação, mas com avaliação da porcentagem de plântulas normais no quarto dia após a semeadura.
Envelhecimento acelerado com solução de $\mathrm{NaCl}$ e $\mathrm{KCl}$ (76 e $87 \% \mathrm{UR}$ ) - utilizou-se o mesmo procedimento do item anterior, porém a água destilada foi substituída por uma solução saturada de $\mathrm{NaCl}$ ou $\mathrm{KCl}(40$ e $32 \%)$, de modo a se obter um ambiente dentro da caixa com 76 e $87 \%$ de UR do ar, respectivamente (JIANHUA \& McDONALD, 1996).

Teor de água - antes e após a aplicação das metodologias dos testes de envelhecimento acelerado (100\%UR, 87\%UR e $76 \%$ UR por $24,48,72$ e 96 horas), o teor de água foi determinado pelo método da estufa a $105 \pm 3^{\circ} \mathrm{C}$ por 24 horas (BRASIL, 1992), utilizando-se duas subamostras de 25 sementes.

Emergência de plântulas em campo - para este teste, foram semeadas, em julho de 2004, quatro subamostras de 100 sementes por lote, em sulcos de quatro metros de comprimento e três centímetros de profundidade, no espaçamento de $25 \mathrm{~cm}$ entre sulcos. Durante a condução do teste, foram realizadas irrigações quando necessário, e a contagem das plântulas emersas foi realizada aos 21 dias após a semeadura. Os resultados foram apresentados em porcentagem(VIEIRA\& CARVALHO, 1994).

Armazenamento - as sementes foram armazenadas em sacos de papel multifoliados por 16 meses, à temperatura de $10^{\circ} \mathrm{C}$ e umidade relativa do ar de $40 \%$, condições de ambiente de armazém adotadas pelas empresas produtoras de sementes de milho-doce. A cada quatro meses, as sementes foram avaliadas quanto à germinação e emergência das plântulas em campo, seguindo a metodologia descrita anteriormente. Antes da instalação dos testes, as amostras dos lotes foram mantidas por três dias em condições de laboratório para que as sementes entrassem em equilíbrio com a temperatura e a umidade relativa do ar ambiente.

A análise de variância foi realizada pelo teste $\mathrm{F}$, em delineamento inteiramente casualizado, e as médias dos tratamentos foram comparadas pelo teste de Tukey a 5\% de significância, e foram realizados os testes das pressuposições da análise de variância. Os dados em porcentagem com valores nulos foram transformados em $(\mathrm{x}+0,5)^{1 / 2} \mathrm{e}$ os demais analisados sem transformação (BARBIN, 2003). Na avaliação das metodologias do teste de envelhecimento acelerado, a análise estatística foi realizada em delineamento inteiramente casualizado, no esquema fatorial $10 \times 3 \times 4$ (lotes x UR x períodos). Realizou-se a determinação dos coeficientes de correlação simples entre os testes capazes de diferenciar os lotes e a emergência de plântulas em campo e germinação nos diferentes períodos de armazenamento das sementes. 


\section{RESULTADOS E DISCUSSÃO}

Os teores de água inicial dos lotes de sementes de milho-doce situaram-se entre 9 e $10 \%$. Essa similaridade de valores é primordial para que os testes não sejam afetados por diferenças na atividade metabólica, velocidade de umedecimento e de deterioração das sementes. Recomenda-se que não haja diferenças maiores que $2 \%$ de teor de água antes do envelhecimento nas amostras de sementes (MARCOS FILHO, 1999).

Após o envelhecimento, para cada método e período estudado, verificou-se que os teores de água continuaram semelhantes entre os lotes de sementes, e isto assegura a credibilidade dos resultados do teste. Nas sementes de milho-doce envelhecidas utilizandose água ( $\mathrm{UR}=100 \%$ ), obtiveram-se valores entre $24,2 \mathrm{e}$ $25,4 \%$ após 24 horas, entre 26,2 e $28,2 \%$ após 48 horas, entre 27,9 e 30,6\% após 72 horas e entre 31,9 e 33,6\% após 96 horas, indicando que a hidratação foi progressiva com o aumento do período de envelhecimento, confirmando relatos de PANOBIANCO \& MARCOS FILHO (2001), SANTOS et al. (2002) e BITTENCOURT \& VIEIRA(2006).

$\mathrm{O}$ uso das soluções salinas saturadas no teste de envelhecimento acelerado tornou a hidratação das sementes de milho-doce mais lenta que a obtida com o uso de água, devido à menor umidade relativa no interior das caixas plásticas, conforme verificado em trabalhos anteriores (JIANHUA \& McDONALD, 1996; PANOBIANCO \& MARCOS FILHO, 2001). O teor de água das sementes submetidas ao envelhecimento com solução de $\mathrm{KCl}(\mathrm{UR}=87 \%)$ permaneceu entre 14,5 e $16,4 \%$, e com $\mathrm{NaCl}$ (UR=76\%) entre 12,4 e 13,4\%, independentemente do período de envelhecimento.

Na tabela 1, verifica-se que as porcentagens de germinação dos lotes de sementes de milho-doce foram estatisticamente equivalentes entre si, e superiores a $60 \%$, que é considerado o valor mínimo para a comercialização de sementes de milho-doce superdoce no Brasil (BRASIL, 2005). Isto é importante, pois um dos objetivos dos testes de vigor é identificar diferenças significativas na qualidade fisiológica de lotes comerciais de sementes com germinação semelhante (MARCOS FILHO, 1999; BITTENCOURT \& VIEIRA, 2006).

Dentre os testes aplicados, somente o teste de condutividade elétrica nos tempos de 6, 8 e 24 horas foi capaz de identificar diferenças entre os lotes, classificando-os em três classes de qualidade (Tabela 2). A condutividade elétrica avaliada após 6 horas de embebição identificou as sementes de um lote de alto vigor (lote 1), um lote de baixo vigor (lote 10) e os demais lotes foram selecionados como de vigor intermediário, porém similar aos demais. Classificação semelhante foi obtida após os períodos de 8 e 24 horas de embebição, embora, para 8 horas, o lote 2 também tenha sido classificado como de alto vigor e, para condutividade avaliada após 24 horas de embebição, o lote 9 tenha sido classificado como de baixo vigor.

Os testes de emergência de plântulas de milho-doce em campo, primeira contagem do teste de germinação, teste de frio, precocidade de emissão de raiz primária (em todos os períodos estudados) e envelhecimento acelerado com água e soluções salinas de cloreto de potássio e de sódio não indicaram

Tabela 1 - Germinação (G), primeira contagem (PC), teste de frio (TF), emergência de plântulas em campo (EC) e precocidade de emissão da raiz primária (PER) na avaliação da qualidade de 10 lotes de sementes de milho-doce híbrido DO-04.

\begin{tabular}{|c|c|c|c|c|c|c|c|c|}
\hline \multirow{2}{*}{ Lotes de sementes } & \multirow{2}{*}{ G } & \multirow[t]{2}{*}{$\mathrm{PC}$} & \multirow[t]{2}{*}{ TF } & \multirow{2}{*}{$\begin{array}{l}\mathrm{EC} \\
(\%)--\end{array}$} & \multicolumn{4}{|c|}{ 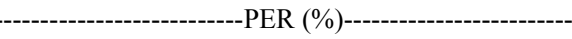 } \\
\hline & & & & & $32 \mathrm{~h}^{2}$ & $48 \mathrm{~h}$ & $56 \mathrm{~h}$ & $72 \mathrm{~h}$ \\
\hline 1 & $79^{1}$ & 62 & 59 & 64 & 3 & 78 & 83 & 89 \\
\hline 2 & 76 & 57 & 65 & 59 & 4 & 78 & 80 & 87 \\
\hline 3 & 75 & 56 & 57 & 70 & 1 & 74 & 81 & 82 \\
\hline 4 & 78 & 59 & 65 & 64 & 5 & 78 & 81 & 83 \\
\hline 5 & 77 & 61 & 56 & 68 & 2 & 77 & 79 & 85 \\
\hline 6 & 77 & 61 & 49 & 60 & 3 & 75 & 79 & 82 \\
\hline 7 & 76 & 60 & 63 & 63 & 3 & 82 & 83 & 87 \\
\hline 8 & 74 & 59 & 57 & 70 & 2 & 72 & 74 & 82 \\
\hline 9 & 76 & 57 & 61 & 62 & 1 & 75 & 80 & 86 \\
\hline 10 & 74 & 57 & 60 & 57 & 6 & 76 & 81 & 86 \\
\hline CV (\%) & 8,1 & 11,3 & 14,4 & 9,0 & 30,0 & 8,9 & 7,7 & 5,9 \\
\hline
\end{tabular}

${ }^{1}$ Médias sem letras na linha não diferem entre si pelo teste $\mathrm{F}(\mathrm{P}=0,05)$.

${ }^{2}$ Para análise, os dados foram transformados em $(x+0,5){ }^{1 / 2}$. Apresentados os valores sem transformação. 
Tabela 2 - Condutividade elétrica $\left(\mu \mathrm{S} \mathrm{cm}^{-1} \mathrm{~g}^{-1}\right)$ na avaliação da qualidade de 10 lotes de sementes de milho-doce híbrido DO-04.

\begin{tabular}{|c|c|c|c|c|c|c|c|c|c|c|c|}
\hline \multirow{2}{*}{ Tempo de Embebição } & \multicolumn{10}{|c|}{ 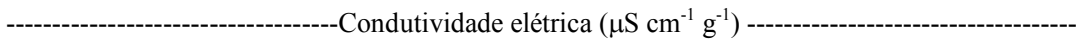 } & \multirow{2}{*}{$\mathrm{CV}(\%)$} \\
\hline & 1 & 2 & 3 & 4 & 5 & 6 & 7 & 8 & 9 & 10 & \\
\hline $4 \mathrm{~h}$ & $35^{1}$ & 35 & 36 & 38 & 35 & 36 & 36 & 38 & 38 & 43 & 8,8 \\
\hline $6 \mathrm{~h}$ & $31 \mathrm{a}$ & $39 \mathrm{ab}$ & $39 \mathrm{ab}$ & $43 \mathrm{ab}$ & $39 \mathrm{ab}$ & $40 \mathrm{ab}$ & $41 \mathrm{ab}$ & $43 a b$ & $43 a b$ & $48 b$ & 16,9 \\
\hline $8 \mathrm{~h}$ & $41 \mathrm{a}$ & $41 \mathrm{a}$ & $43 \mathrm{ab}$ & $46 \mathrm{ab}$ & $42 \mathrm{ab}$ & $42 \mathrm{ab}$ & $44 \mathrm{ab}$ & $47 \mathrm{ab}$ & $45 \mathrm{ab}$ & $51 b$ & 8,9 \\
\hline $24 \mathrm{~h}$ & $43 a$ & $44 \mathrm{ab}$ & $53 \mathrm{ab}$ & $54 \mathrm{ab}$ & $49 \mathrm{ab}$ & $47 \mathrm{ab}$ & $46 \mathrm{ab}$ & $47 \mathrm{ab}$ & $57 \mathrm{~b}$ & $57 \mathrm{~b}$ & 10,4 \\
\hline
\end{tabular}

${ }^{1}$ Médias seguidas pela mesma letra na linha, ou sem letras, não diferem entre si pelo teste $\mathrm{F}(\mathrm{P}=0,05)$.

diferenças estatísticas de vigor entre os lotes de sementes estudados, da mesma forma que a germinação, e isso não permitiu a diferenciação qualitativa dos mesmos (Tabelas 1 e 3). Os resultados divergem dos obtidos por SANTOS et al. (2002), no envelhecimento acelerado de sementes de milho-doce BR-400 com água.

No teste de envelhecimento acelerado das sementes de milho-doce, também não foram verificadas diferenças estatísticas entre as três condições de condução (água, solução de $\mathrm{KCl}$ e de $\mathrm{NaCl}$ ), os períodos de envelhecimento ( 48,72 e 96 horas) e para as interações entre esses fatores e lotes (Tabela 3).

A qualidade fisiológica dos 10 lotes de sementes de milho-doce foi similar durante o armazenamento, não diferindo estatisticamente quanto à germinação e emergência de plântulas em campo aos 4, 8, 12 e 16 meses (Tabela 4).

A similaridade de desempenho dos lotes de sementes de milho-doce superdoce híbrido DO-04 shrunken-2 (sh2) verificada pela maioria das características avaliadas pode ser atribuída ao intenso controle dos fatores de produção adotados pelas empresas de sementes, devido ao alto valor econômico e às dificuldades de produção dessas sementes com alta qualidade fisiológica, pois sementes desse híbrido são mais suscetíveis a danos mecânicos, patógenos e deterioração, quando comparadas às sementes de milho comum e de outras espécies (WATERS \& BLANCHETTE, 1983). Assim, mesmo em lotes provenientes de diferentes campos pode haver qualidade fisiológica similar, uma vez que as sementes são produzidas em áreas irrigadas, com condições climáticas ideais para milho-doce, o que possibilita a colheita em período seco e de baixa temperatura. Adicionalmente, as máquinas de colheita e beneficiamento são reguladas e, muitas vezes, adaptadas para evitar danos mecânicos às sementes.

Neste trabalho, somente o teste de condutividade elétrica selecionou, estatisticamente, os lotes em classes de vigor (Tabela 2) e, por isso, foi submetido à análise de correlação com a germinação e

Tabela 3 - Teste de envelhecimento acelerado com água $\left(\mathrm{EA} \mathrm{H}_{2} \mathrm{O}\right)$, solução de cloreto de potássio (EA $\mathrm{KCl}$ ) e de cloreto de sódio (EA $\mathrm{NaCl}$ ), na avaliação da qualidade de 10 lotes de sementes de milho-doce híbrido DO-04.

\begin{tabular}{|c|c|c|c|c|c|c|c|c|c|c|c|c|}
\hline \multirow{2}{*}{ Lotes de sementes } & \multicolumn{4}{|c|}{------------EA $\mathrm{H}_{2} \mathrm{O}$ (\%)------------ } & \multicolumn{4}{|c|}{------------EA KCl (\%)------------ } & \multicolumn{4}{|c|}{------------EA NaCl (\%)---------- } \\
\hline & $24 \mathrm{~h}$ & $48 \mathrm{~h}$ & $72 \mathrm{~h}$ & $96 \mathrm{~h}$ & $24 \mathrm{~h}$ & $48 \mathrm{~h}$ & $72 \mathrm{~h}$ & $96 \mathrm{~h}$ & $24 \mathrm{~h}$ & $48 \mathrm{~h}$ & $72 \mathrm{~h}$ & $96 \mathrm{~h}$ \\
\hline 1 & $58^{1}$ & 64 & 63 & 63 & 67 & 58 & 61 & 55 & 57 & 64 & 58 & 61 \\
\hline 2 & 58 & 64 & 64 & 66 & 63 & 58 & 62 & 56 & 63 & 52 & 56 & 59 \\
\hline 3 & 59 & 60 & 64 & 62 & 65 & 56 & 56 & 52 & 59 & 59 & 54 & 56 \\
\hline 4 & 65 & 63 & 65 & 62 & 63 & 53 & 66 & 55 & 57 & 55 & 58 & 59 \\
\hline 5 & 60 & 64 & 57 & 65 & 62 & 56 & 57 & 54 & 58 & 53 & 58 & 59 \\
\hline 6 & 63 & 68 & 64 & 60 & 60 & 51 & 63 & 56 & 59 & 52 & 58 & 55 \\
\hline 7 & 65 & 64 & 67 & 60 & 65 & 56 & 62 & 54 & 60 & 57 & 58 & 56 \\
\hline 8 & 65 & 57 & 62 & 57 & 67 & 50 & 60 & 56 & 63 & 53 & 57 & 56 \\
\hline 9 & 60 & 62 & 61 & 56 & 62 & 49 & 54 & 50 & 60 & 54 & 56 & 56 \\
\hline 10 & 58 & 69 & 64 & 58 & 56 & 58 & 61 & 53 & 62 & 58 & 56 & 59 \\
\hline CV $(\%)$ & & & & & & & & & & & & \\
\hline
\end{tabular}

${ }^{1}$ Médias sem letras no teste de envelhecimento acelerado na comparação entre lotes, umidade relativa e períodos não diferem entre si pelo teste de $\mathrm{F}(\mathrm{P}=0,05)$.

Ciência Rural, v.39, n.9, dez, 2009. 
Tabela 4 - Efeito do armazenamento das sementes sobre a germinação e emergência de plântulas em campo de 10 lotes comerciais de sementes de milho-doce híbrido DO-04.

\begin{tabular}{|c|c|c|c|c|c|c|c|c|c|c|c|}
\hline \multirow{2}{*}{ Armazenamento } & \multicolumn{10}{|c|}{ 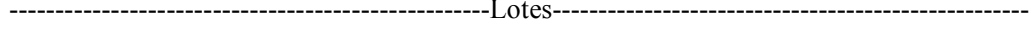 } & \multirow{2}{*}{$\mathrm{CV}(\%)$} \\
\hline & 1 & 2 & 3 & 4 & 5 & 6 & 7 & 8 & 9 & 10 & \\
\hline \multicolumn{12}{|c|}{--------------------------------------------------------------------Germinação (\%)-------------------------------------------------------------------- } \\
\hline 0 meses & $79^{1}$ & 76 & 75 & 78 & 77 & 77 & 76 & 74 & 76 & 74 & 8,1 \\
\hline 4 meses & 80 & 79 & 78 & 76 & 73 & 75 & 71 & 74 & 75 & 75 & 9,2 \\
\hline 8 meses & 77 & 77 & 76 & 75 & 68 & 74 & 68 & 70 & 71 & 75 & 10,1 \\
\hline 12 meses & 78 & 73 & 73 & 71 & 67 & 70 & 66 & 67 & 70 & 70 & 10,5 \\
\hline 16 meses & 67 & 67 & 66 & 65 & 60 & 61 & 59 & 60 & 61 & 62 & 10,7 \\
\hline & & & $---E r$ & ência & lântu & $\mathrm{m}$ car & $(\%)$ & & - & & -------- \\
\hline 0 meses & 64 & 59 & 70 & 64 & 68 & 60 & 63 & 70 & 62 & 57 & 9,0 \\
\hline 4 meses & 73 & 71 & 71 & 70 & 63 & 67 & 62 & 65 & 66 & 67 & 9,4 \\
\hline 8 meses & 64 & 63 & 60 & 59 & 55 & 56 & 53 & 55 & 56 & 58 & 16,9 \\
\hline 12 meses & 57 & 56 & 55 & 55 & 48 & 51 & 46 & 49 & 50 & 54 & 15,3 \\
\hline 16 meses & 44 & 43 & 42 & 41 & 39 & 39 & 38 & 39 & 39 & 40 & 19,5 \\
\hline
\end{tabular}

Médias sem letras na linha não diferem entre si pelo teste $\mathrm{F}(\mathrm{P}=0,05)$.

emergência de plântulas em campo nos diferentes períodos de armazenamento das sementes. No entanto, a análise estatística identificou valores de coeficiente de correlação simples $(\mathrm{R})$ inferiores a 0,58 , entre condutividade elétrica e germinação, e inferiores a 0,62 , entre condutividade elétrica e emergência de plântulas em campo. As correlações não apresentaram significância estatística em todos os tempos de armazenamento estudados, não agregando informações elucidativas à interpretação dos dados obtidos. Este procedimento de estudo tem sido adotado em trabalhos sobre testes de vigor em sementes, pois a similaridade entre as ordenações dos valores obtidos, associada à análise da relação de dependência entre o teste de vigor promissor e a emergência das plântulas em campo, ou longevidade no armazenamento, são características desejadas (BRAZ et al., 2008).

\section{CONCLUSÃO}

Dentre os testes avaliados (primeira contagem, precocidade de emissão de raiz primária, teste de frio, condutividade elétrica e envelhecimento acelerado), a condutividade elétrica ( 6,8 e 24horas) é o único eficiente na diferenciação do vigor de lotes de sementes de milho-doce (sh2). Não há correlação entre os testes e a emergência de plântulas em campo e geminação após armazenamento.

\section{AGRADECIMENTO}

À Fundação de Apoio à Pesquisa do Estado de São Paulo (FAPESP), pelo auxílio à pesquisa.

\section{REFERÊNCIAS}

BARBIN, D. Planejamento e análise de experimentos agronômicos. Arapongas: Midas, 2003. 208p.

BITTENCOURT, S.R.M.; VIEIRA, R.D. Temperatura e período de exposição de sementes de milho no teste de envelhecimento acelerado. Revista Brasileira de Sementes, v.28, n.3, p.61-168, 2006. Disponível em: $<$ http://www.scielo.br/scielo.php?script=sci_arttext\&pid=S010131222006000300023\&lng=pt\&nrm=iso $>$. ISSN 0101-3122. Acesso em: 30 jul. 2009. doi: 10.1590/S0101-31222006000300023.

BRASIL, Ministério da Agricultura e Reforma Agrária. Regras para análise de sementes. Brasília: SNDA/DNDV/CLV, 1992. $365 \mathrm{p}$.

BRASIL, Ministério da Agricultura, Pecuária e Abastecimento. Padrões para produção e comercialização de sementes de milho-cultivares híbridas. Instrução normativa n.25, de 16 de dezembro de 2005. Diário Oficial da União, sec.1, n.243, p.18 de 20/12/2005, 2005. Disponível em: <http:// extranet.agricultura.gov.br/sislegis-consulta/servlet/ VisualizarAnexo?id=10811>. Acesso em: 30 jul. 2009.

BRAZ, M.R.S. et al. Testes de envelhecimento acelerado e deterioração controlada na avaliação do vigor de aquênios de girassol. Ciência Rural, v.38, n.7, p.1857-1863, 2008. Disponível em $<$ http://www.scielo.br/scielo.php?script=sci arttext\&pid=S0103$84782008000700009 \& \operatorname{lng}=$ pt\&nrm=iso $>$. Acesso em: 30 jul. 2009. doi: $10.1590 / \mathrm{S} 0103-84782008000700009$.

DELOUCHE, J.C.; BASKIN, C.C. Accelerated aging techniques for predicing the relative storability of seed lots. Seed Science and Technology, v.1, n.2, p.427-452, 1973

HAMPTON, J.G.; TEKONY, D.M. Handbook of vigour test methods. Zürich: ISTA, 1995. 117p.

JIANHUA, Z.; McDONALD, M.B. The saturatede salt accelerated aging test for small-seeded crop. Seed Science and Technology, v.25, n.1, p.123-131, 1996. 
MARCOS FILHO, J. Teste de envelhecimento acelerado. In: KRZYZANOWSKY, F.C. et al. Vigor de sementes: conceitos e testes. Londrina: ABRATES, 1999. p.3.1-3.24.

PANOBIANCO, M.; MARCOS FILHO, J. Envelhecimento acelerado e deterioração controlada em sementes de tomate. Scientia Agrícola, v.58, n.3, p.525-531, 2001. Disponível em $<$ http://www.scielo.br/scielo.php?script=sci_arttext\&pid=S010390162001000300014\&lng=pt\&nrm=iso $>$. Acesso em: $30 \mathrm{jul}$. 2009. doi: 10.1590/S0103-90162001000300014.

SANTOS, P.M. et al. Avaliação da qualidade fisiológica de sementes de milho-doce pelo teste de envelhecimento acelerado. Revista Brasileira de Sementes, v.24, n.1, p.91-96, 2002.
TOLEDO, F.F. et al. Vigor de sementes de milho (Zea mays L.) avaliado pela precocidade de emissão da raiz primária. Scientia Agricola, v.56, n.1, p.191-196, 1999. Disponível em <http:/ /www.scielo.br/scielo.php?script $=$ sci_arttext\&pid $=$ S010390161999000100026\&lng=pt\&nrm=iso $>$. Acesso: em: 30 jul. 2009. doi: 10.1590/S0103-90161999000100026.

VIEIRA, R.D.; CARVALHO, N.M. (Eds.) Testes de vigor em sementes. Jaboticabal: FUNEP, 1994. 164p.

WATERS, L.; BLANCHETTE, B. Prediction of sweet corn field emergence by conductivity and cold tests. Journal of American Society Horticultural Science, v.108, n.5, p.78$781,1983$. 